\title{
Video-assisted thoracic sympathectomy in the treatment of primary hyperhidrosis
}

\author{
José Ribas Milanez de Campos, Paulo Kauffman
}

Recent advances in optical and video systems, as well as in instruments for endoscopic surgical procedures, have made it possible to perform video-assisted thoracic sympathectomy, ${ }^{(1)}$ a safe, effective, minimally-invasive procedure with low morbidity and better acceptance by patients. As a consequence, in the 1990s, various studies, most conducted in Europe and Asia but and some conducted in North America, called attention to this technique. ${ }^{(2,3)}$

Primary hyperhidrosis is currently the principal indication for video-assisted thoracic sympathectomy. It occurs predominantly on the hands (palmar form), in the armpits (axillary form), and on the feet (plantar form) but can also manifest in the craniofacial segment. Palmoplantar hyperhidrosis generally appears in childhood, and tends to worsen in adolescence, a phase of life in which there is great psychological instability. Axillary hyperhidrosis manifests in adolescence, when sex glands become active.

Hyperhidrosis affects both genders equally. However, the fact that women are, by nature, more susceptible to adverse psychological impacts and, consequently, more often seek treatment, gives the impression that hyperhidrosis is more prevalent in females. ${ }^{(4)}$ In the present issue of the Brazilian Journal of Pulmonology, Montessi et al. report data related to 521 patients undergoing surgical procedures for this condition. ${ }^{(1)}$

The authors report only the most cranial level of the section of the sympathetic chain, in the three groups analyzed, not revealing the extent of the thermal ablation performed. In our experience, despite conflicting opinions in the literature on the importance of the extent of the cauterized or resected chain in compensatory or reflex sweating, this side effect can be minimized through more conservative sympathectomies, involving only one ganglion of the sympathetic chain, without jeopardizing the final result of the procedure. ${ }^{(5)}$ The current consensus in the literature is that the preservation of the second ganglion of the sympathetic thoracic chain does not decisively affect the result of the intervention, either on the hands or in the armpits, and it is of fundamental importance in order to reduce the intensity of compensatory sweating, as observed by Montessi et al., ${ }^{(1)}$ as well as by our group. ${ }^{(6)}$ 1nitially, in our routine procedures involving this ganglion, we found that $64 \%$ of the patients presented compensatory hyperhi- drosis (moderate or intense sweating) in other areas of the body, and that 4\% regretted having undergone the surgical procedure. ${ }^{(3)}$

The description of the method employed in the study conducted by Montessi et al. is highly summarized, and there is no reference to the type of anesthesia used. ${ }^{(1)}$ In our earlier studies, we routinely used a double-lumen probe, with selective blockage of the lung ipsilateral to the operated lung. ${ }^{(2,4)}$ The experience acquired made it possible for us to use this approach only when we treated the fourth ganglion of the sympathetic chain. When the intervention was performed in the ganglia that are more cranially located, a simple probe sufficed and was less traumatic in the intervention. ${ }^{(3)}$

Other aspects were not reported by the authors, ${ }^{(1)}$ including the number of incisions made and the type of scalpel used in the thermal ablation of the sympathetic chain. Initially, we used an electric scalpel, which was subsequently replaced with advantage by a harmonic scalpel, which has the advantage of allowing cleaner dissection without carbonization of the tissues, resulting in an apparent reduction in postoperative pain. ${ }^{(3)}$ ln the vast majority of cases, we used two $0.5 \mathrm{~cm}$-long incisions in each hemithorax. A third incision was made only if technical difficulties arose. Montessi et al. also neglected to mention any criteria for exclusion from candidacy for the surgical procedure. We wonder if patients with a history of pleuropulmonary diseases or thoracic surgery were included in this study sample. That seems unlikely, since the article does not mention any firm pleural adhesions that would render the sympathicotomy unfeasible. Nor did the authors report any patients with loose pleural adhesions, which are typically found by surgeons who perform video-assisted thoracic sympathectomy and would be expected in such a large study sample. ${ }^{(1)}$ We have used the following exclusion criteria: previous thoracic surgery; pleural diseases; heart diseases; neoplasms; and overweight status (body mass index $>25 \mathrm{~kg} / \mathrm{m}^{2}$ ). ${ }^{(5)}$

Some confusion remains in the literature regarding the level of action in the sympathetic chain. In the study in question, the authors used the letter $\mathrm{T}$ to indicate the costal arch level, rather than to indicate the sympathetic ganglion, as in most articles published. Since the authors do not provide a thorough description of the technique used, 
we infer, from the data available, that they only performed a sympathicotomy (section of the chain over the costal arches), rather than a sympathectomy, the way we perform it (section of the chain over the costal arches and thermal ablation of the segment of the chain located between them, which contains the corresponding sympathetic ganglion), the latter procedure impeding the regeneration of the chain due to the proximity of the stumps, which, in a sympathicotomy, are simply sectioned. ${ }^{(3)}$ Therefore, the title of their study should begin with 'Video-assisted thoracic sympathicotomy' rather than 'Video-assisted thoracic sympathectomy'.

There is no reference, in the article by Montessi et al., to the length of the follow-up period, and the low index of failure (they do not report recurrence of hyperhidrosis over time) is surprising. This leads us to conclude that the results presented are premature, since we had the opportunity to observe, in a postoperative follow-up period of one year, recurrence of the manifestation in $8.2 \%$ of the patients with palmar hyperhidrosis and in 13.7\% of the patients with axillary hyperhidrosis. ${ }^{(7)}$

Hyperhidrosis is a clinical manifestation that significantly interferes with the quality of life of the individual. Therefore, the results of its treatment should be judiciously evaluated by applying a quality of life questionnaire in which various domains of human activity are taken into consideration. Although this approach is routinely employed in the Outpatient Hyperhidrosis Clinic of the University of Sao Paulo School of Medicine Hospital das Clínicas, ${ }^{(7)}$ it was not adopted by the authors. (1)

As shown by Montessi et al., the intensity of reflex sweating is reduced in direct relation to the level of the intervention on the sympathetic thoracic chain (lower level = less reflex sweating). This is in concordance with the data in the literature, as well as with ours. ${ }^{(5,6)}$ However, the significance of this side effect increases in overweight or obese patients. Therefore, surgical intervention is contra-indicated in such patients, ${ }^{(8)}$ an observation not made in the Montessi et al. study. ${ }^{(1)}$

The approach routinely taken by the authors, ${ }^{(1)}$ performing sympathicotomy over the fourth costal arch in the treatment of palmar hyperhidrosis, merits scrutiny. In our experience, thermal ablation of the fourth ganglion of the sympathetic thoracic chain (T4) for the treatment of palmar hyperhidrosis does not result in anhidrosis of the hands in a signi- ficant number of patients. However, it significantly decreases the intensity of previous sweating in the extremities, as well as reflex sweating, with a high level of patient satisfaction. In most patients with palmar hyperhidrosis, we currently prefer to perform thermal ablation of the third ganglion of the sympathetic thoracic chain (T3).; In select patients, we have performed thermal ablation, but only after those patients have been duly informed of the advantages and disadvantages of the procedure. In fact, we should take into consideration the expectations of the patient regarding palmar hyperhidrosis, since most desire anhidrosis of the extremities.

Montessi et al. did not mention the effects that the operation had on plantar hyperhidrosis. Since the great majority of patients who present palmar hyperhidrosis present plantar hyperhidrosis as well, more than half, in our experience, present improvement of the plantar hyperhidrosis after thoracic sympathectomy, although there is no convincing anatomical or physiological explanation for this fact. ${ }^{(3)}$

The subjective evaluation of the patients regarding the degree of their reflex sweating does not always correspond to reality, as the authors themselves admit.(1) However, there are no objective methods of quantifying such sweating. Therefore, we use a semi-objective criterion in this evaluation, taking into consideration information obtained from the patient regarding the level of discomfort, influence on social and professional activities, and the need to change clothing, together with objective observations of the examiner. ${ }^{(5)}$

\section{José Ribas Milanez de Campos $\mathrm{PhD}$ and Assistant Professor in the Department of Thoracic Surgery of the University of São Paulo - USP - São Paulo (SP) Brazil}

\author{
Paulo Kauffman \\ Assistant Professor in the Department of \\ Vascular Surgery of the University of São \\ Paulo (USP) - São Paulo (SP) Brazil
}

\section{References}

1. Montessi J, Almeida EP, Vieira JP, Abreu MM, Souza RLP, Montessi OVD. Simpatectomia torácica por videotoracoscopia para tratamento da hiperidrose primária: estudo retrospectivo 
de 521 casos comparando diferentes níveis de ablação. J Bras Pneumol. 2007;33(3):248-254

2. Kauffman P, Milanez JRC, Jatene F, Leão PP. Simpatectomia cervicotorácica por vídeotoracoscopia : experiência inicial. Rev Col Bras de Cir. 1998;(25):235-9.

3. Kauffman P, Milanez JRC, Wolosker N, Kuzniec S, Jatene FB, Leão PP. Simpatectomia cervicotorácica videotoracoscópica: experiência de 8 anos. J Vasc Bras. 2003;2(2):98-104.

4. Milanez JRC, Kauffman P, Ghefter MC. Simpatectomia cérvico-torácica por vídeo-toracoscopia. In: Sociedade Paulista de Pneumologia e Tisiologia. Pneumologia Atualização e Reciclagem. 6 ed. São Paulo: Vivali; 2001.

5. Munia MA, Wolosker N, Kauffman P, de Campos JR, Puech-Leao P. A randomized trial of T3-T4 versus T4 sympathectomy for isolated axillary hyperhidrosis. J Vasc Surg. 2007;45(1):130-3.

6. Yazbek G, Wolosker N, de Campos JR, Kauffman P, lshy A, Puech-Leao P. Palmar hyperhidrosis--which is the best level of denervation using video-assisted thoracoscopic sympathectomy: T2 or T3 ganglion? J Vasc Surg. 2005;42(2):281-5.

7. de Campos JR, Kauffman P, Werebe Ede C, Andrade Filho LO, Kusniek S, Wolosker N, et al. Quality of life, before and after thoracic sympathectomy: report of 378 operated patients. Ann Thorac Surg. 2003;76(3):886-91.

8. de Campos JR, Wolosker N, Takeda FR, Kauffman P, Kuzniec $\mathrm{S}$, Jatene FB, et al. The body mass index and level of resection: predictive factors for compensatory sweating after sympathectomy. Clin Auton Res. 2005;15(2):116-20. 